\title{
Development of Removable Visual Impact Indicator or Polymer Composite Materials
}

\author{
Sergejs VIDINEJEVS *, Olga BULDERBERGA, Andrey ANISKEVICH
}

Institute for Mechanics of Materials, University of Latvia, Riga, LV-1004, Latvia

crossref http://dx.doi.org/10.5755/j02.ms.27206

Received 08 July 2020; accepted 13 October 2020

\begin{abstract}
The prototype of removable visual impact indicator for thermoset polymer composite materials is developed, and its characteristics are experimentally determined. The indicator is a fabric tape glued by epoxy to the surface of the polymer composite. The tape is impregnated with a composition that provides a visual response at the place of an impact on the composite surface. Ball-drop tests demonstrated the increase of the magnitude of the visual response with the impact energy at different substrate hardnesses. The shelf-life and mode of the tape storage until commissioning are determined. Peel tests showed the ability to remove a used indicator without damaging the surface of the composite.

Keywords: impact indicator, removable indicator, microcapsules, adhesive tape, ball-drop test, peel test.
\end{abstract}

\section{INTRODUCTION}

A rapid and extensive engineering application of fiberreinforced polymer (FRP) composite materials is being observed in aerospace, transport, and other high-performing industries. The high strength- and modulus-to-weight ratios in the reinforcement direction, as well as corrosion resistance, are key factors of this process. Nevertheless, the composite matrix (usually a thermoset polymer) tends to brittle fracture. Composites itself have a lack of damage tolerance due to their inherent anisotropy and low transversally-shear strength. These factors restrain the trend of metal substitution in different applications. External mechanical static and dynamic loads, including sudden and adverse impacts of foreign objects, cause different defects and damages. They often manifest itself internally within the material and are invisible on the surface of structural composite members, but can lead to their serious weakening and even failure [1-4]. Not promptly detected and not eliminated residual damage can lead to both performance period reduction - and failure with catastrophic consequences.

Traditional non-destructive testing (NDT) methods for structural health monitoring of composite products, e.g., optical methods (thermography, shearography), acoustic emission, computer tomography, ultrasonic diagnostic, electric resistance measurements, etc. [5], often require: (1) removal or detachment of the component from the structure to be evaluated, (2) prolonged time for inspection of large structures, (3) expensive response analysis using spectralmethod apparatuses and qualified staff (the cost of this inspection is approximately one-third of acquiring and operating in load-bearing-aircraft composite structures [6]).

Initial inspection based on a non-instrumental visual indication of impacts could concentrate efforts of NDT to a limited area of the impact instead that to the entire structure and thus provide lower maintenance costs of the structure.
The concept of visual indication of impacts involves the incorporation of leuco-dye-filled microcapsules into the surface layer or coating of the composite structure. Microcapsules have the advantage of keeping core materials stable for a long time and triggering visual response only when broken down under the impact or excessive strain. The dye released changes from colorless to colorful with halochromic reaction caused by $\mathrm{pH}$ change in contact with a developer (particles, fillers of other capsules, etc.). A colored stain leaves on the surface of the structure as the response to the impact [7-10]. Optimal implementation implies that the observable response appears only after such an impact that causes mechanical damage in the interior of the material.

If visual impact indicators are in forms of composite surface layers or films, the main problems are the complexity and high cost of harmonization of chemical, physical, and mechanical properties of these layers or films with load-bearing composite materials. The following examples illustrate the severity of the part of the problem. The amines of a traditional hardener for uncured epoxy resin have an alkaline reaction [11] and deactivate the developer, which usually has an acidic reaction [12]. Commonly, microcapsules are dispersed in water to remain intact during storage and prevent aggregation tendencies. The water environment hinders the direct introduction microcapsules into such binders as epoxy. Besides, harmonization should occur at the stage of manufacturing a composite structure.

A possible way to avoid the harmonization problem is to separate the composite structure itself and the indicator layer, which can be in the form of a tape with a glue, can be removed, like a traditional adhesive tape. Such thin visual indicator could be useful not only for mentioned reinforced polymer composites, but moreover for any substrates where traces of impacts are unnoticeable and to which it could be glued. In this case, chemical, physical, and mechanical properties must be harmonized within the framework of this

\footnotetext{
${ }^{*}$ Corresponding author. Tel.: +371-29112855.

E-mail address: sergejs.vidinejevs@pmi.lv (S. Vidinejevs)
} 
tape only, without changing the designed composite structure itself. The indicator tape must have a sufficient shelf-life, the long-term ability for visual response in the adherent state. The peel (removable) force of the tape after employing must be less than that of the surface fiber layer of the composite construction itself [13].

Thus, a chromatic removable visual impact indicator could become a mean for visually recording the place of mechanical impact on the surface of the structure at the production stage, storage, or exploitation. The mentioned impact has the energy or makes pressure on the surface, which is above a definite threshold value. The first use of this indicator is to locate impact loadings quickly. Future development of the indicator could also allow determining the type, direction, and area of other external mechanical static and dynamic loads.

The main goal of the present work was to develop a prototype of removable visual impact indicator first for fiber-reinforced thermoset polymer composite materials. Corresponding tasks of the work are:

- Development of laboratory technology for the manufacture of the indicator.

- Experimental confirmation of the main functional property-indication of the place of impact for substrates with significantly different hardness.

- Experimental confirmation of the essential employment and operational properties of the prototype - shelf life, indicator removal (peel strength).

\section{MANUFACTURE OF INDICATOR PROTOTYPE}

A prototype of visual impact indicator is intended for its gluing to the surface of polymer composite finished products and composite structural members. The impact indicator designed would be stored for a long time prior to use, observing the minimum material storage requirements (deposited on a flat surface and the absence of an external load on the surface). The well-known "prepreg" principle can be used as an example for the development of the prototype technology. According to this principle, fiber reinforcements and their binder impregnations are kept uncured. For this purpose, a reinforcing fabric will be preimpregnated with a resin system. This resin system (typically epoxy) already includes the proper curing agent. For the laminate to cure, it is necessary to use a combination of pressure and heat [14].

As a core of the prototype, the indicator layer preforms elaborated earlier [9] were selected. Thus, the fabric as a framework was impregnated with commercial color former microcapsules and color developer particles mixed with modified polyurethane acrylate as a binder, and then cured together to obtain a preform. The presence of this binder gave advantages over the direct admixing of the dye microcapsules and developer into the epoxy. The capsules, their core, and particles of the developer had additional chemical and mechanical protection. The cured preform could be easily wetted and saturated with uncured epoxy resin. The particles of the developer were also reliably protected from the hardener.
A laboratory method of the manufacture of the prototype of the impact indicator included several steps:

1. A primary impregnation of selected fabric tape (typically a polyamide (nylon) Stitch Ply A (AIRTECH Europe Sarl) fabric with surface density $88 \mathrm{~g} / \mathrm{m}^{2}$ ) was implied to make the preform mentioned. Constituents of the impregnating compound were industrial microcapsules of leuco dye with particles of an acidic developer in the forms of water dispersion (Papierfabrik August Koehler AG) and commercial epoxy-modified polyurethane-acrylate emulsion HALWEDROL UV 20/40W (Koninklijke DSM N.V.), all at a pre-selected optimal ratio. The fabric impregnated was dried in a suspended state and then was subjected to UV-irradiation to provide polymerization of the latest emulsion component (see [9]). A fraction of the impregnating composition constituted $68 \pm 5 \%$ of the initial surface density of the substrate fabric.

2. After primary impregnation, the preform was cut into bands, which had to be additionally impregnated with epoxy binder (bisphenol-A resin and cycloaliphatic-polyamine hardener) suitable for a room-temperature curing. In this study, for generality, two types of epoxy resin with different performances were tested to manufacture two prototypes of indicators. Type I was resin LH 289 with hardener H 289 (ratio 100:33, Havel Composites CZ s.r.o.) This epoxy resin has an extremely low viscosity. The advantage of mixtures of resin and hardener is its clarity. When curing, the epoxy offers high mechanical, thermal, and chemical resistance properties. It is suitable both to produce composites and topcoats of finished products. Type II was highperformance epoxy resin EL 160 with hardener EL 160 (ratio 100:35, Easy Composites Ltd.). The latest one is usable at service temperatures up to $170{ }^{\circ} \mathrm{C}$ ). Besides, acetone was added to this mixture in the amount of 5 and 20 wt.\%. In this step, the impregnation was implemented by brush, and then the excess binder was removed by a polytetrafluoroethylene (PTFE) roller on a PTFE plate. No additional control of the amount of epoxy impregnation was carried out in the manufacture of the indicator prototypes. Thus, the preform was getting a form of the prepreg of indicator tape. For the typical nylon carcass fabric with a thickness of $0.16 \mathrm{~mm}$, thickness estimates impregnated in two steps and cured was $0.22 \pm 0.01 \mathrm{~mm}$. A small scatter in thicknesses would suggest an equally small scatter in sensitivity of the indicator prototypes.

3. The prepreg of indicator tape was wrapping into a polyethylene terephthalate film to storage in anti-adhesive and moisture resistant conditions and to be resistant to mechanical stresses. Air bubbles existed were removed by a soft rubber roller. The prepreg wrapped was tightly packed into an additional film and sealed by adhesive tape. The package was tightly wound on cardboard reels and fixed with adhesive tape (Fig. 1).

Summarizing, one can conclude that the prototype of indicator tape manufactured has a prepreg form - fabric impregnated with uncured epoxy for gluing to substrates and prepared for storage. The fabric has been preliminarily saturated with constituents preserved for the ability of a halochromic reaction - a change in the color of the dye released from microcapsules upon a contact with particles of the acidic developer in the case of an impact. 


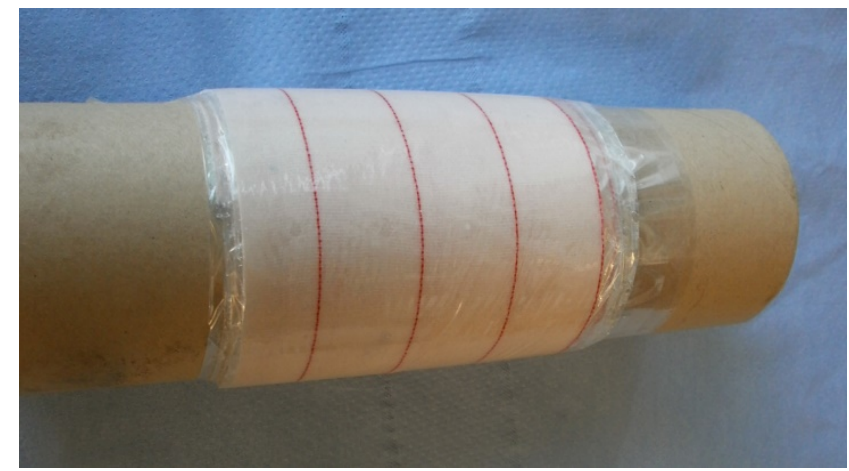

Fig. 1. The ready prototype of the indicator

\section{INDICATION OF IMPACTS}

The main exploitation property of the prototype developed is the visual indication of impact places with the color change there. We proceed from the assumption that the thin indicator will be glued onto a thicker and more massive substrate. The effective characteristics of the combination will differ slightly from those of the substrate itself. In other words, the presence of the indicator will not affect the nature of the damage that the substrate can receive because of the impact. In this study, when it is necessary to demonstrate the fact of visual indication of impacts, the nature and properties of the substrate are not important. A visual response of the indicator is seen in the form of dark stain, in which the dye released has changed color via halochromic reaction. This response appears with absorption in indicator tape of a small part of the kinetic energy of an impact. The rest of most kinetic impact energy first is converted to structural deformation of the substrate, which follows Hertzian contact laws and then is spent to the creation of damage [15]. In this case, isotropic material the contact laws have the simplest form. Substrates of such materials for gluing indicator tape samples can serve as the simplest models of bulk composites. It is expected that the magnitude of the visual response (area of the stain after impact) of the indicator will primarily depend on elastic and yield characteristics of the substrates. A steel-ball indentation hardness correlates with the characteristics mentioned. In this study, two isotropic substrates with the hardnesses of $9.8 \pm 1.0$ and $0.28 \pm 0.01 \mathrm{~Pa}-$ "hard" (PTFE) and "soft" (polyurethane foam) correspondingly, were used as substrates for demonstration magnitude of the visual response. Type I epoxy impregnant served as an adhesive for gluing the indicator to both substrates. The indicatorsubstrate combinations were exposed to impacts of a dropped steel sphere of diameter $31.7 \mathrm{~mm}$ and weight $130 \mathrm{~g}$.

By the falling height change from 300 to $3000 \mathrm{~mm}$, the impact energy of the sphere $E$ changed from about 0.4 to $4 \mathrm{~J}$, respectively. The dependence between the area of a circular stain $A$ after impact and the impact energy $E$ was investigated experimentally for both combinations of indicator-substrate. After ball-drop tests on the soft substrate, some of visual responses had shapes other than circular, see Fig. 2 a, because indicator-substrate interface was inhomogeneous owing existing in the foam macroscopic voids filled or not with epoxy. On the hard substrate, visual responses with a clearly identified border, were observed, see Fig. 2 c. Thus, for the image data treatment on both substrates, the compromise solution was needed. To measure the damaged area, Adobe ${ }^{\circledR}$ Photoshop ${ }^{\circledR}$ software tools were used. For the separation of the visual response zone from the background, Color Range Tool was applied. This tool allowed selecting a user-defined color range. The range of selected colors was adjusted by entering a Fuzziness value. In the center of the visual response zone, where the darkest visual response was expected, the color was selected using 11 pixels sized Eyedropper Tool. For the visual responses on soft substrate, the selected area with the Fuzziness value 50 more precisely corresponded with the visual response area. Around the visual response area, the barely visible color change was also observed. To consider the color change in the barely visible zone Fuzziness value was increased to 70, to absolutely exclude it Fuzziness 30 was applied, see Fig. $2 \mathrm{~b}$ and Fig. $2 \mathrm{~d}$. The obtained selections were colored on new layers. These colored selections were cut and transferred to separate layers. The number of colored pixels in each damage zone was measured with Histogram tool and recalculated to the values of area $A$. By this procedure, an interval of $A$ values of visual response for the same impact energy was obtained, which was considered as a measuring error.

The experimental dependences of visual response area $A$ vs. the impact energy $E$ for the prototype of the indicator tape glued to soft and hard substrates are presented in Fig. 3. It is seen that area $A$ rises monotonically in the studied range of impact energy and is greater for softer substrate at the same impact energy and the same geometry of dropping body.

\section{Fuzziness}
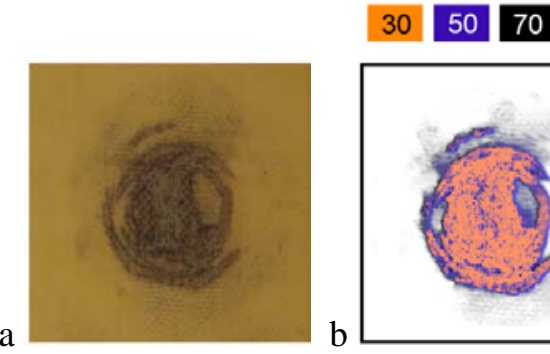
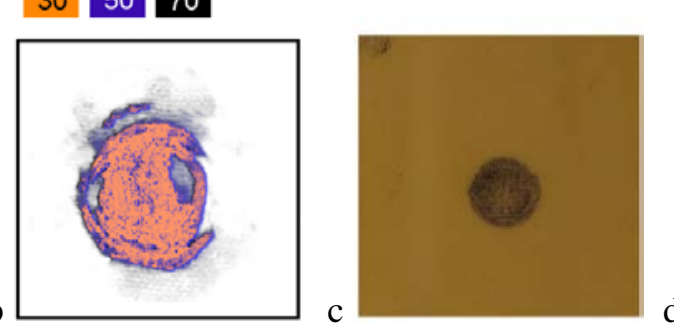

\section{Fuzziness \\ $3 0 \longdiv { 5 0 } 7 0$}

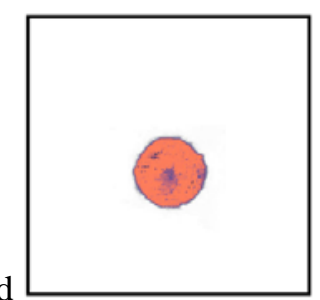

Fig. 2. The visual response obtained on the: a-soft; c-hard substrates after $1.5 \mathrm{~J}$ impact. Selected areas for the data treatment with Fuzziness levels 30,50 , and 70 on the: $b$-soft; $d$-hard substrates 


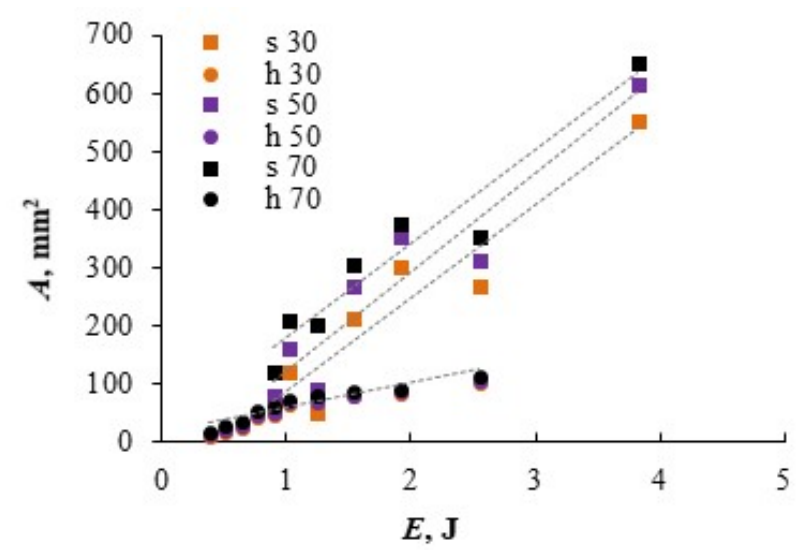

Fig. 3. Area of visual response $A$ depending on the impact energy E. Values obtained with Fuzziness levels 30, 40, and 70 (painted as in Fig. 2) for soft (sø) and hard substrates (h•)

The experimental results confirm the main functional property of the indicator - to indicate the place of impact by a stain. It is obvious that the two-dimensional area of the stain on the indicator after impact cannot coincide with the space of possible damage to the substrate. The indicator is not able to provide information on the nature of possible failure in the substrate after the impact due to the complex nature of the absorption of energy in the deformable volume of the composite [15], and additional instrumental examination of this place will be required. Nevertheless, for substrates that are significantly different in hardness, it is possible to indicate different impact energies of corresponding ranges by the visual response of different magnitude (area). It increases with energy, which may be useful to estimate a consequence of the impact.

\section{SHELF LIFE OF PROTOTYPE}

The shelf life of the prototype of visual indicator is an important employment property, which is strongly affected by storage conditions [16, 17]. In this study, reduced storage temperatures (common for the composite prepreg storage) and acetone (diluter of uncured epoxy) were used to develop optimal storage conditions (from the view of maximum shelf life) of the indicator prototypes in a form of prepreg. In practice, five rolls of indicator-tape samples (see Section 2, Fig. 1) in the shape of strip tape with approximately one-meter length were prepared. Type I and II epoxy binders were used without acetone and with acetone (5 and $20 \mathrm{wt} . \%)$. Some of the rolls were placed in a refrigerator (temperature $+2{ }^{\circ} \mathrm{C}$ ), the other ones - in a freezer $\left(-18^{\circ} \mathrm{C}\right)$. Starting from the first day, little pieces of the prepreg tapes were cutting off with scissors from the rolls. After sealing in the film, the remainders of the tapes were returned to continue the low-temperature storage.

Phenolic resin laminate (textolite) was chosen as a substrate with a thermoset binder. Textolite can be easily adhered using epoxy to FRP composites. The cut pieces were destined to gluing onto this substrate using a soft rubber roller in the next few minutes. On examination, if the piece looked wet with epoxy and was pliable, and the next day after gluing remained attached to the substrate, it was considered that the prototype prepreg could continue to be stored successfully. Correspondingly, the expiration was noted when the prepreg ceased to adhere to the substrate. It meant that the first criterion (A - the ability to adhere the prepreg to the substrate), when assessing the shelf life, is not met. The above check of the prepregs was every day for the first 10 days, after three to four days for the next 10 days, and then once a week.

Results of the storage experiment from the criterion A fulfillment for the samples of prepreg are shown in Fig. 4.

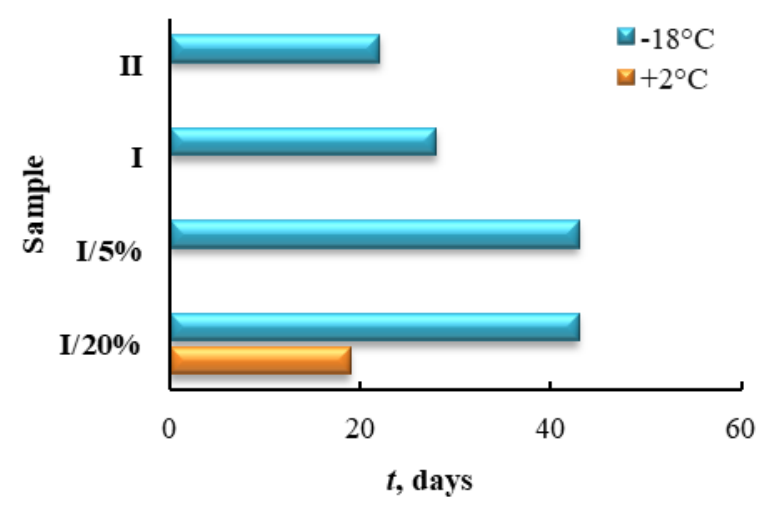

Fig. 4. Comparison of the storage times (criterion A fulfillment) for samples of the prepreg of the prototype. Sample designation - epoxy type/acetone wt.\%

Storage experiments demonstrated that all tape samples keep the ability to be glued to the substrate, for the period around 20 days regardless of storage temperature. Adding of acetone and descending of storage temperature down to $-18{ }^{\circ} \mathrm{C}$ allowed getting greater (exceeding 40 days) shelflife. The second criterion (B), when assessing the shelf life, was to maintain the ability to indicate impacts by the halochromic reaction. To quickly check it, experiments were carried out to indent each indicator sample glued to a textolite substrate. Criterion B was always satisfied. The experiments did not show any decrease in the indication activity of the prototypes without and with 5 and 20 wt.\% acetone in the uncured binder by the storage.

The results of the studies in this Section mean the possibility of delivering a manufactured visual impact indicator to a remote consumer for attachment to a substrate, for example, a structural element made of polymer composite. The shelf-life results confirmed the important employment property necessary for the commercial and logistic promotion of the prototype with conditions like traditional prepregs.

\section{PROTOTYPE REMOVAL (PEEL STRENGTH)}

Adhesion properties to the substrate of the cured indicator tapes are important operational properties that influence the application area of the indicator. After indicator removal, extra efforts could be required for removal of its traces from the substrate surface. At the other extreme, during the removal of the indicator, the top fibrous layer of the composite substrate could adhere to the indicator tape and break out. Potential fiber breaks could result in high rework costs. To evaluate strength for indicator prototype removal from the substrate, peel tests were used.

Considering the previous results that the presence of $5 \%$ or $20 \%$ acetone does not affect the shelf life, the 
samples I/5 \% (epoxy with acetone) of the prototype were made and tested. To check the influence of the type of carcass fabric, three types of fabric were used:

- $\quad$ Stitch Ply A (AIRTECH Europe Sarl.), nylon, density $88 \mathrm{~g} / \mathrm{m}^{2}$ (traditionally used in preforms as a peel ply, because it could be easily stripped off of cured laminate, it has red tracers with high visibility to reduce the risk of peel ply being left on the part [19].

- $\quad$ E-glass fiber fabric (Valmiera SSR), density $125 \mathrm{~g} / \mathrm{m}^{2}$.

- $\quad$ E-glass fiber fabric (Valmiera SSR), density $160 \mathrm{~g} / \mathrm{m}^{2}$.

Samples of three types of fabric tapes with the size $15.5 \mathrm{~mm}$ width and at least $20 \mathrm{~cm}$ length were prepared applying laboratory technology as described in Section 2 and placed on the freezer at temperature $-18{ }^{\circ} \mathrm{C}$. At certain time intervals, the samples were taken from the freezer and adhered to the textolite substrate. Samples were stored for $24 \mathrm{~h}$ at $+45^{\circ} \mathrm{C}$ to cure the binder. After the specimens were conditioned at room temperature, they were subjected to a peel test. A peel angle $90^{\circ}$ was chosen for tests because the peel force usually reaches the highest value at this angle [13].

The peel test employed was analogous to [18]. The universal electromechanical testing machine Zwick 2.5 was equipped with a specially designed grip to fix the substrate and to ensure the removal of the indicator prototype at an angle of $90^{\circ}$ (Fig. 5). The displacement rate of the grips was $2 \mathrm{~mm} / \mathrm{s}$. The typical force-displacement curve is shown in Fig. 6. A large scatter in the instantaneous peel force was observed, reflecting a stick-slip nature of the process of breaking the bond between the indicator and the substrate. The reasons for this were the geometric and chemical heterogeneity of the cured impregnation/adhesive at the interface and its low flexibility. The peel strength was determined as the average force per unit width of bondline required to separate progressively the indicator tape from the rigid textolite substrate. The peel strength, which is proportional to the peel strength, also had a high scatter.

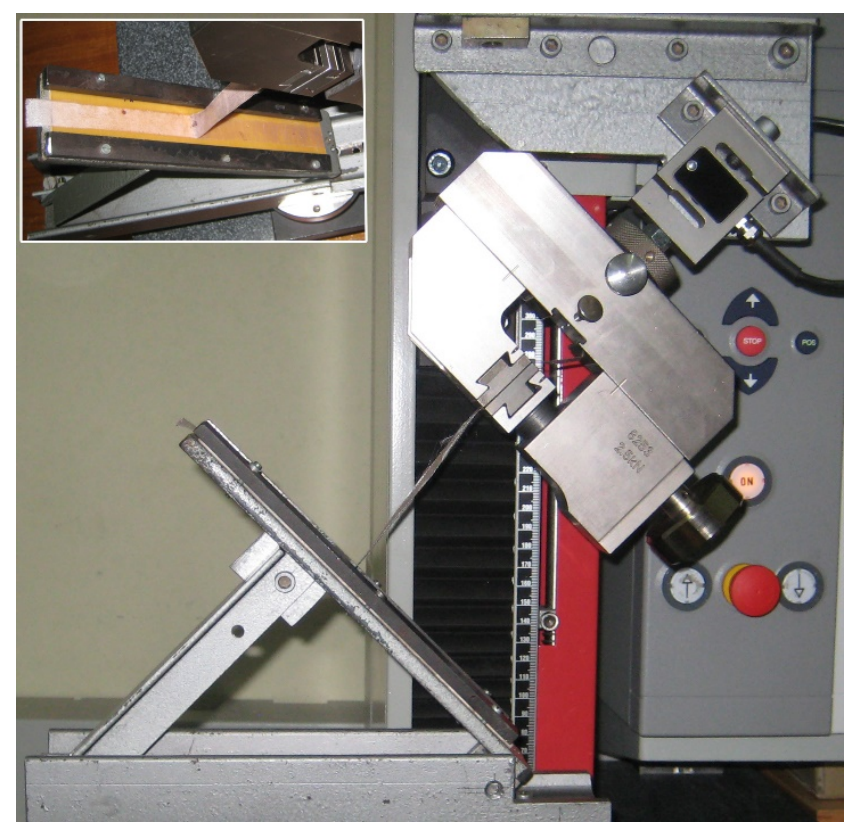

Fig. 5. Specially designed fixture for Zwick 2.5 to ensure the peel off the indicator prototype sample (see the inset)

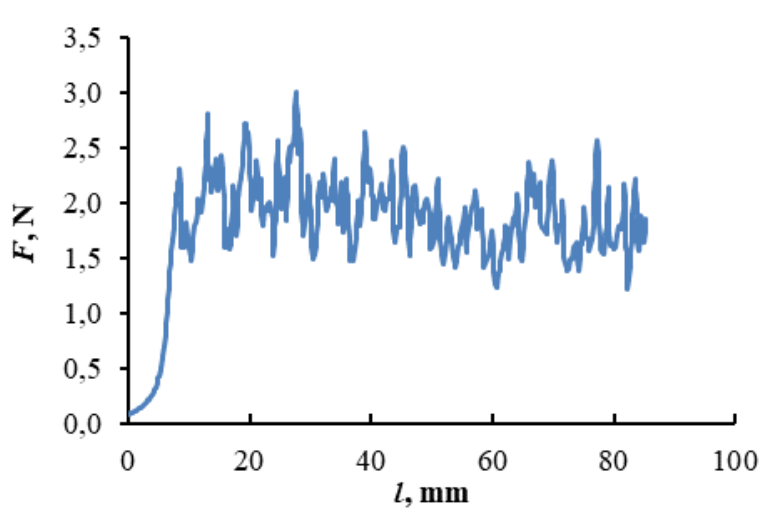

Fig. 6. The typical force-displacement $F-l$ curve obtained during the peel test

During the peel tests, the relation between peel strength and time of specimen storage in the freezer was studied. The results for prototype samples on a base of nylon and glass fiber tapes are presented in Fig. 7.

Results of the tests showed that the peel strength decreasing started after 45 days of storage that confirmed the results of the experiments assessing the shelf life (see Section 4). The prototypes prepregs with glass fabric carcass, especially glass fabric $125 \mathrm{~g} / \mathrm{m}^{2}$ had a lower shelflife, comparing to nylon-based prepreg, but had higher peel strength (Fig. 7).

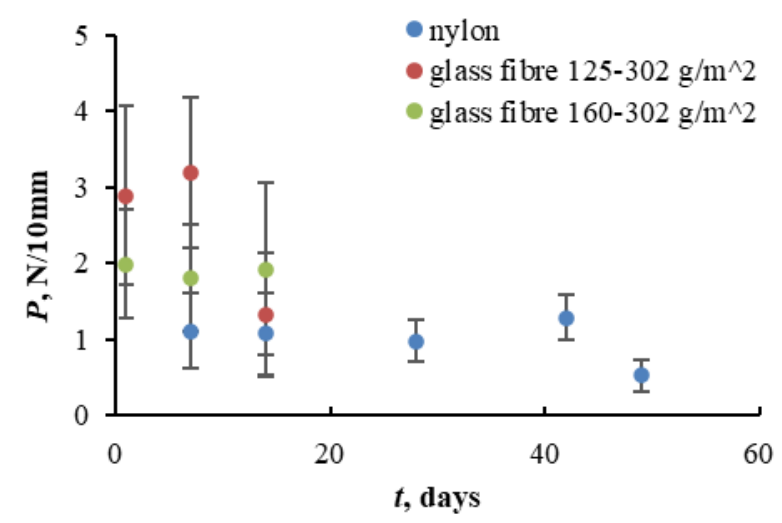

Fig. 7. Peel strength $P$ vs. time of storage in freezer $t$ for indicator prototype samples with nylon and glass fabric carcass. Error ranges reflect one standard deviation of the peel strength

At glass fiber intersection points, existing cavities can be more filled with epoxy compared to those at nylon fiber. These points can work as mechanical interlocking sites with a surface of the substrate [20] thus providing higher peel strength. Peel strengths obtained for the prototypes with a glass fabric carcass $2-3 \mathrm{~N} / 10 \mathrm{~mm}(200-300 \mathrm{~N} / \mathrm{m})$ are in $2-3$ times higher compared to that of with a nylon carcass $1 \mathrm{~N} / 10 \mathrm{~mm}(100 \mathrm{~N} / \mathrm{m})$, but at least twice smaller than the usual forces for removing peel plies used in the manufacturing process of reinforced composites [13]. If these plies do not violate the integrity of the composite, then the indicator prototype will be innocuous for the composite layers. In other words, the developed indicators will not damage the substrate composite when the indicator tape is removed. The traces of the complex impregnation, which also served as the binder of the indicator prototype and the 
substrate, partly remain on the surface of the composite. The removed indicator tape and the traces on the substrate surface are colored in contrast to the glued yet tape (Fig. 8).

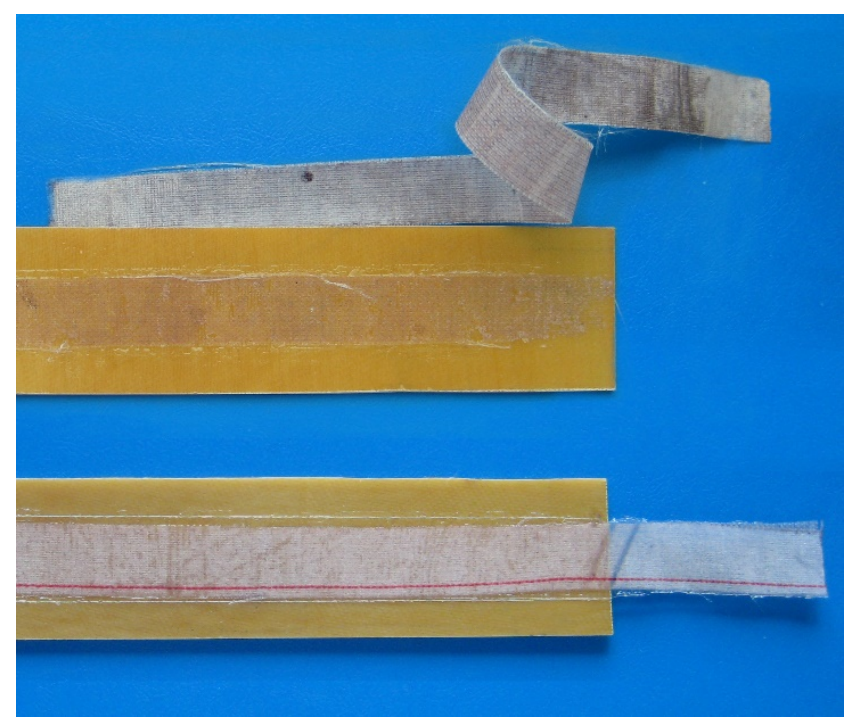

Fig. 8. The dark surface of textolite and the tape itself after the indicator prototype removal as well initial tape for comparison

This can be explained by the fact that the separation occurs mainly across the weakest adhesive of the first step impregnation and is accompanied by damage to the microcapsules with the subsequent halochromic reaction. Correspondingly, the base binder of the substrate remains undisturbed without any consequences for the integrity of the upper layer of the material at the end of indicator exploitation and its removing from the inspected area. The need for some additional surface cleaning appears to be a small fee for using the removable visual impact indicator. The above can be fully attributed to the main types of FRP composites based on epoxy, polyester, and other matrices, for use with which the indicator prototype developed is primarily intended.

\section{CONCLUSIONS}

The prototype developed of removable visual impact indicator is suitable for any substrate materials which are susceptible to mechanical impact damages, but do not manifest impact traces on their surface. The material must also be adherable to epoxy binder. The most important employment of the prototype is using for surfaces of fiberreinforced thermoset polymer composite materials. The prototype employs the halochromic reaction of a dye microencapsulated (industrial product) for visual indication of impacts. The elements of composite-prepreg storage methods are used for the prototype storage.

The main functional and operational properties are verified:

- The ability to visually respond to the impact with the dark stain, area of which depends on the impact energy and hardness of the composite substrate.

- The ability to store the indicator tape in the form of a prepreg for more than a month at a freezer temperature.
- $\quad$ The ability to remove the indicator from the inspected area without any serious consequences or damages on the surface of the substrate.

- The latest two properties (storage time and peel strength) are partly controlled by changing the tape carcass material.

The experimentally proven properties of the prototype confirm the effectiveness of the concepts used. The prototype development of removable visual impact indicator is a key process to develop and create a successful product.

\section{Acknowledgments}

This study was funded by the Latvian Council of Science, project 'Durability and environmental stability of microcapsule-filled polymer composites with smartinteraction capability' No. lzp-2018/1-0084. The authors gratefully acknowledge Prof. S. B. Sapozhnikov from South Ural State University (Russia) for his input in a deeper understanding of the prepreg manufacture process and practical advice. The authors acknowledge technician Mr. G. Lasko for his help in the digital treatment of images.

\section{REFERENCES}

1. Trask, R.S., Williams, H.R., Bond, I.P. Self-Healing Polymer Composites: Mimicking Nature to Enhance Performance Bioinspiration \& Biomimetics 2 (1) 2007: pp. P1 - P9.

https://doi.org/10.1088/1748-3182/2/1/P01

2. Rhead, A.T., Butler, R. Compressive Static Strength Model for Impact Damaged Laminates Composites Science and Technology 69(14) 2009: pp. 2301-2307. https://doi.org/10.1016/j.compscitech.2009.01.010

3. Mathijsen, D. Structural Health Monitoring: Composite Skins Are Getting a Nervous System. Reinforced Plastics 59 (3) 2015: pp. 139-142. https://doi.org/10.1016/j.repl.2015.02.013

4. Kovaḷovs, A., Ručevskis, S., Kulakov, V., Wesolowski, M. Optimum Position of Electrodes to Detect Delaminations in Composite Materials Using the Electric Resistance Change Method Mechanics of Composite Materials 55 2020: pp. 811-818. https://doi.org/10.1007/s11029-020-09852-y

5. Gholizadeh, S. A Review of Non-Destructive Testing Methods of Composite Materials Procedia Structural Integrity 1 2016: pp. 50-57.

https://doi.org/10.1016/j.prostr.2016.02.008

6. Diamanti, K., Soutis, C. Structural Health Monitoring Techniques for Aircraft Composite Structures Progress in Aerospace Sciences 46 (8) 2010: pp. 342-352. https://doi.org/10.1016/j.paerosci.2010.05.001

7. Vidinejevs, S., Aniskevich, A.N., Gregor, A., Sjöberg, M., Alvarez, G. Smart Polymeric Coatings for Damage Visualization in Substrate Materials Journal of Intelligent Material Systems and Structures 23 (12) 2012: pp. $1371-1377$. https://doi.org/10.1177/1045389X12447289

8. Odom, S.A., Jackson, A.C., $\quad$ Prokup, A.M., Chayanupatkul, S., Sottos, N.R., White, S.R., Moore, J. S. Visual Indication of Mechanical Damage Using Core-Shell Microcapsules ACS Applied Materials \& Interfaces 3 (12) 2011: pp. $4547-4551$.

https://doi.org/10.1021/am201048a 
9. Vidinejevs, S., $\quad$ Strekalova, O., $\quad$ Aniskevich, A., Gaidukov, S. Development of a Composite with an Inherent Function of Visualization of a Mechanical Action Mechanics of Composite Materials 49(1) 2013: pp. 77-84. https://doi.org/10.1007/s11029-013-9323-9

10. Li, W., Matthews, C.C., Yang, K., Odarczenko, M.T., White, S.R., Sottos, N.R. Autonomous Indication of Mechanical Damage in Polymeric Coatings Advanced Materials 28 (11) 2016: pp. 2189-2194. https://doi.org/10.1002/adma.201505214

11. Yuan, Y.C., $\quad$ Rong, M.Z., Zhang, M.Q., Chen, J., Yang, G.C., Li, X.M. Self-Healing Polymeric Materials Using Epoxy/Mercaptan as the Healant Macromolecules 41 2008: pp. $5197-5202$. https://doi.org/10.1021/ma800028d

12. Thies, C. Microencapsulation. In Encyclopedia of Polymer Science and Technology. 2004. https://doi.org/10.1002/0471440264.pst198

13. Buchmann, C., Langer, S., Filsinger, J., Drechsler, K. Analysis of the Removal of Peel Ply from CFRP Surfaces Composites Part B 89 2016: pp. $352-361$. https://doi.org/10.1016/j.compositesb.2015.11.019

14. Prepreg. Fibre Glast Development Corporation (available https://www.fibreglast.com/product/aboutprepregs/Learning_Center).
15. Dhanisetty, V.S.V., $\quad$ Massart, P.F.R., $\quad$ Esrail, F., Verhagen, W.J.C., Kassapoglou, C. Prediction of Damage Due to Impact for Composites on the Basis of Possible Impact Threats International Journal of Impact Engineering 132 2019: p. 103317.

https://doi.org/10.1016/j.ijimpeng.2019.103317

16. Storage and Handling of Prepregs. The Fibre Reinforced Plastic \& Composite Technology Resource Centre (available at http://www.fibre-reinforced-plastic.com/2010/03/storageand-handling-of-prepregs.html).

17. Prepreg Technology. Hexcel Corporation. 2013 (available https://www.hexcel.com/user_area/content_media/raw/Prepr eg_Technology.pdf).

18. ASTM D6862-11(2016). Standard Test Method for 90 Degree Peel Resistance of Adhesives (available https://www.astm.org/Standards/D6862.htm).

19. Peel Ply. Fibre Glast Development Corporation (available https://www.fibreglast.com/product/econostitch_peel_ply/V acuum_Bagging_Films_Peel_Ply_Tapes).

20. Kanerva, M., Saarela, O. The Peel Ply Surface Treatment for Adhesive Bonding of Composites: A Review International Journal of Adhesion and Adhesives 43 2013: pp. $60-69$. https://doi.org/10.1016/j.ijadhadh.2013.01.014 